\title{
INTRODUÇĀO A GARCIA MORENTE
}

Guillermo de la Cruz-Coronado

O professor Manuel García Morente (1886-1942) é bem conhecido entre os brasileiros estudiosos da filosofia; seu nome penetrou no Brasil anos atrás, sobretudo mercê do livro que agora apresentamos traduzido pela primeira vez à língua portuguêsa $\left({ }^{*}\right)$. Este livro desde sua primeira publicação em língua espanhola (Buenos Aires, 1938, Editorial Losada, S.A.) tem estado presente para quase todos os mestres e alunos brasileiros de filosofia; tem atuado em função do ensino da filosofia, principalmente para a vivência do pensamento dos grandes vultos da filosofia no passado. O êxito editorial dêste livro proclama seu raro mérito. Exito realmente extraordinário, dado o grande número de ediçōes em poucos anos, e mais tomando em conta o reduzido público que em qualquer parte do mundo se interessa pelos estudos de filosofia. Na sua forma originária, com o texto exclusivo de Garcia Morente e com o título de "Lecciones Preliminares de Filosofia", que reúne suas lições na Universidade de Tucumán durante o curso de 1937, foi impresso cinco vêzes na Argentina sòmente de 1938 a 1952. Na forma ampliada, com lições posteriores do autor em Universidades espanholas (a lição IX: "O classicismo de Santo Tomás de Aquino" e a lição XII: "Análise ontológica da fé") e com as lições complementares do professor Juan Zaragüeta (da XXVI à XXIX), amigo e colega de professorado de Garcia Morente na Universidade de Madrid nos últimos dias de seu magistério filosófico, foi impresso na Espanha outras cinco vêzes só entre 1943 e 1960 (Espasa Calpe, Madrid).

Essas lições têm semeado filosofia - amor, simpatia $\epsilon$ gôsto pela filosofia - em tôdas as nações de língua espanhola;

(•) Este trabalho serve de apresentação à minha traduçăo no livro "Fundamentos de Fllosofia", do professor García Morente, lançado recentemente pela editóra Mestre Jou, de Såo Paulo. 
mas, não sòmente nelas; as lições filosóficas de Garcia Morente difundiram-se por entre nações de outras línguas, especialmente nas de língua portuguêsa, por razões óbvias de proximidade e contacto cultural e de facilidade de compreensão para o texto espanhol. Poucos serão os profissionais, os amadores e os escolares da filosofia em Portugal e Brasil, que não conheçam estas aulas magníficas de García Morente e não se tenham utilizado delas; poucos serão aquêles que não lhe devam alguma coisa. Para quem compreender quão necessária é, ao filosofar pessoal, a presença viva do passado filosófico da humanidade, fácil lhe será conceder ao filósofo espanhol uma parcela de mérito e de contribuição na difusão dos estudos filosóficos no Brasil.

O que Garcia Morente significa para a filosofia hispânica moderna nos foi já dito por alguns de seus colegas e discípulos da escola filosófica de Madrid; mas não passam de apontamentos esquemáticos e superficiais; falta infelizmente um trabalho a fundo sôbre o assunto, que nós não podemos empreender agora. Nossa pretensão se reduz a apresentar o grande mestre da filosofia para o público brasileiro contribuindo assim à melhor compreensão do livro que traduzimos.

Com sua atitude, a um tempo clarividente e humilde, ante os problemas filosóficos e suas possíveis soluções; com sua singela renúncia a qualquer individualismo exagerado, a qualquer projeção absorvente do eu sôbre a objetividade dos problemas; com sua larga e dinâmica compreensão dos pontos de vista mais opostos em filosofia, foi García Morente, entranhàvelmente, um filósofo. $\mathrm{E}$ um filósofo integral, com tôdas as dimensões de um filósofo de "garra", não um brilhante erudito ou um simples amador ou um mero professor repetidor de pensamentos alheios. Filósofo integral e profissional, enquanto o profissional implica em vocacional, e não em simples ofício. Filósofo integral, mas a seu modo, porque, como dizia Aristóteles do ser, também ser filósofo, ser verdadeira e integralmente filósofo, se diz de vários modos.

García Morente teve seu modo de ser filósofo e de sê-lo com autenticidade. Não lhe faltou nenhuma das dimensões exigidas para ser filósofo no sentido pleno dessa dificílima tarefa que é o filosofar. Dimensões várias que podem reduzir-se a 
três: historicidade, pensamento pessoal, e transmissão. Com raríssimas exceções, todos os grandes filósofos foram, ao mesmo tempo, em medidas diferentes, repensadores criticos da fiIosofia anterior, elaboradores de um pensamento pessoal e semeadores de filosofia.

O filósofo de verdade começa (nem sempre êste começar é cronológico) refazendo por si mesmo o caminho percorrido pela filosofia desde seu nascedouro. Começa colocando-se a si próprio nas perspectivas das grandes mentes que souberam suscitar e ampliar a complexa problemática da filosofia através da história, procurando compreendê-las, torná-las vivência pessoal; vivência, esta palavra tão expressiva da filosofia moderna, que os escritores da famosa "Revista de Ocidente", de Madrid, entre os quais se contava o nosso García Morente, introduziram tão acertadamente na língua espanhola, traduzindo o vocábulo "Erlebnis" do alemão, e transmitida depois fraternalmente à língua portuguêsa.

Sem vivência do passado filosófico, sem um refazimento de sua problemática e de seus logros e malogros, é precário o exercício da crítica tão indispensável a todo filósofo que se preze. Sem uma prévia visão retrospectiva, sem uma visão do passado incidindo sôbre o presente, é impossível ao filósofo situar-se dentro do seu próprio tempo, dentro do seu momento histórico; é impossível ao filósofo tornar-se e reconhecer-se representante do seu tempo, como filósofo em que as raízes do pensar afundam junto às raízes do viver, êsse viver que é de hoje, do tempo de cada um, se quer ser expoente lídimo do avanço da humanidade. Porque de todos os saberes nenhum é tão compulsòriamente histórico como o saber do filósofo, 0 saber da filosofia. Outros saberes ou ciências (penso nas ciências naturais ou nas físico-matemáticas, ou nas matemáticas puras) aceitam os resultados do seu evoluir histórico, bastando-lhes o aproveitamento dêsses resultados sem sentir-se atados à gênese histórica dos mesmos. Mas os saberes da cultura - e mais a filosofia - sentem-se em qualquer etapa com seu cordão umbilical ligado à sua gênese e evolução histórica; na filosofia, mais do que em nenhuma outra ciência do espírito, a sua história se constitui em parte de si mesma, porque a construção histórica da filosofia, a história da filosofia, é já um filosofar, é já filosofia. Dai que todo filósofo em plenitude co- 
mece (não se trata, repito, de um começar cronológico, embora também muitas vêzes é cronológico) por refazer pessoalmente a história da filosofia para conhecer sua situação nêsse caminhar secular da filosofia, sua situação como homem do seu tempo.

De todos os filósofos espanhóis de sua geração talvez nenhum realizou com tanta intensidade como Garcia Morente essa dimensão de mergulhar-se na historicidade da filosofia; talvez nenhum fêz tão repetidas e demoradas viagens pela história da filosofia como García Morente. Durante sua vida de filósofo, o catedrático de tica da Universidade de Madrid consagrou grande parte de seu tempo a compreender o pensamento dos mais altos filósofos debruçando-se pacientemente sôbre os textos originais; produto dêsse trato cotidiano com os livros mais representativos da filosofia, são suas traduções de Descartes, Kant, Bergson, Spengler, Rickert, etc.; traduções que marcam época na renovação do pensamento filosófico espanhol contemporâneo e que são obras mestras no gênero pela sua fidelidade e pela penetração nos textos originais. Do seu mergulho na historicidade é também prova palpável o presente livro. Nascido com a intenção inicial de umas excursões exploradoras (a imagem pertence a García Morente) pelos territórios da filosofia, já de comêço nos apresenta o autor a divisão em dois territórios, ambos perfeitamente filosóficos, o histórico e o doutrinal. Quem o ler atentamente, perceberá que nêste livro o histórico não é um simples pórtico externo, mas parte integrante da própria filosofia, a primeira parte da filosofia. Em consequência de sua colocação no plano inicial, García Morente dedica a primeira parte a uma excursão pela história da filosofia, excursão que ocupa a maior parte das lições de sua autoria. O complemento da parte doutrinal, com as lições do professor Zaragüeta, não diminui, no conjunto definitivo, o espaço material da parte histórica, antes serve para confirmar sua importância e sua posição de primeiro território da filosofia, de território por onde começa a filosofia, por onde deve começar o filosofar, a tarefa do filósofo. $\mathrm{E}$ com esta conviç̧ão, empreende García Morente, levando-nos consigo ,sua viagem pelo campo histórico da filosofia. Mas, que história da filosofia! Que deliciosa excursão para os companheiros de viagem que foram seus ouvintes e para todos os fu- 
turos leitores, intre os quais estamos nós! E uma grata caminhada por entre vastas paisagens, iluminadas ou ensombradas, mas sempi : ocupadas pelos grandes problemas do ser. Pois, se filosofia é, antes de tudo, metafísica, ontologia, a história da filosofia é principalmente a história das problematizações, a história do pensamento humano radicado no ser, como diz o próprio García Morente, expressando seus propósitos na obra, "nāo se trata simplesmente de um repertório de doutrinas, mas principalmente de que nós, tocìs juntos, uns e outros, vivamos durante uns instantes essas realidades his. tóricas que sāo as grandes doutrinas metafísicas sôbre o ser" (n. ${ }^{\circ} 88$, final).

O grifado é meu, e serve para dar relêvo ao propósito de García Morente: vivência conjunta, com-vivência entre companheiros de caminhada, e convivência das grandes paisagens históricas da metafísica. Realmente, não é que convivamos em igualdade; é êle, o mestre, o guia que nos faz viver, que nos faz participar de sua vivência, que nô-la transmite fazendo-a nossa, que nos faz com-viver com êle as mais profundas doutrinas metafísicas. $E$ que calor nessa convivência das realidades históricas da metafísica! Vemo-nos transpostos como por arte mágica, essa magia que é sua arte de aproximar-nos às coisas simples, natural, quase insensivelmente. Primeiro, 0 mundo grego; sentimo-nos pelas ruas Atenas, ou na ágora, observando o afanar de um povo ocioso, cujo ócio era pensar e problematizar e tentar resolver. Sentimo-nos mergulhados no viver citadino dos filósofos gregos, participando dos seus problemas, querendo compreendê-los e tentando fazê-los nossos como devotados discipulos. $\mathbf{E}$ isto, sem o que se costuma chamar reconstruções históricas; só com alguns toques de intuição que abrem ante nós essa realidade histórica, e nela o aparecer natural dos homens pensantes com os olhos cheios do ser. Parmênides, fixado no uno e total; Heráclito, olhando o fluir do rio que nunca volta a ser o mesmo, o rio imagem do seu "panta rei"; Zenão, lançando Aquiles atrás da tartaruga; e Sócrates, Platão, Aristóteles, essa trindade encadeada e sucessiva de personagens que é a melhor expressāo da alma do povo grego, suscitando problemas nos seus circunstantes, argüindo, raciocinando, provocando e aceitando o diálogo; sobretudo isto, o diálogo, porque o pensamento grego se estru- 
tura no diálogo, vive dêle e para êle; o pensamento grego é uma conversação animada, uma conversa entre concidadãos que espalha idéias, que as troca, faz seu jôgo e serve depois para a meditação interior. $\mathbf{E}$ assim que García Morente anima ante nossos olhos - como em conversa ou em simpósio (palavra e realidade no viver grego) - a figura de Sócrates com sua aretê - que não é pròpriamente virtus mas harmonia, equilíbrio - a de Platão com suas idéias ultra-terrestres e, em contraste, a de Aristóteles com suas coisas manuais, com suas coisas como são, como as vemos e utilizamos, com essas coisas em que êle deposita suas meditações sôbre o ser.

Depois nos introduz no pensamento tomista como representante do mais sublime filosofar da Idade Média; para García Morente Santo Tomás é um clássico aberto, como o mar, para receber todos os rios da verdade. $\mathrm{E}$ logo o autor nos leva a acompanhá-lo no nôvo mundo renascentista para realizar com êle o giro coperniciano aplicado à metafísica. A análise da reviravolta metafísica que anuncia o mundo moderno, está efetuada com uma dialética tão magistral que vemos com o olhar angustiado como os seres reais, as substâncias manuais do aristotelismo, vão se apagando, se esfumando, desde Descartes até Hume, para desvanecer-se com Kant no incognoscível. A maestria com que García Morente nos leva a seguir passo a passo o evoluir histórico do pensamento racionalista de Descartes até Hume, em paisagens sucessivas e rápidas em que o ser, obscurecendo-se mais e mais, fugindo mais e mais do sol pleno da objetividade, vai se perdendo pelo mato fundo da subjetividade; e o soberano gesto com que nos descortina o panorama do otimismo leibnitziano com suas raízes metafísicas, sua projeção científica físico-matemática e sua culminaçâo teológica, só estão superados pelas lições que dedica ao idealismo transcendental.

Difícil será ao leitor encontrar outra história da filosofia que, tão sintèticamente e ao mesmo tempo tão vivamente, lhe ofereça as coordenadas básicas do pensamento kantiano; García Morente nos introduz progressiva, imperceptìvelmente, até atingir o âmago áspero e nada atraente do sistema kantiano, nos instala nele com una facilidade surpreendente; essa facilidade dificilima a que chegou o autor depois de muitos anos de assimilação pessoal e de lida escolar com Kant. 
Nessas lições históricas Gai ?ía Morente não pretende elaborar uma história completa da filosofia; são lições funcionais, são lições em função do tema metafísico que é o núcleo de sua obra. Por isso a excursão historicista visa a descobrir diante de nós os grandes e opostos campos do pensamento ontológico: realismo e idealismo, simbolizados pelos seus realizadores mais plenos, Aristóteles e Kant; e assim assistimos ao desenrolar-se histórico dos dois problemas basilares da ontologia: o pròpriamente metafísico, o da realidade, o do ser enquanto ser, enquanto "é algo em si", enquanto "é", enquanto "algo" e enquanto "em si"; e o problema gnoseológico, o do conhecimento do ser, do ser enquanto "ser para mim", "objeto para mim". Problemas nucleares, ìntimamente enlaçados no equacionamento e na solução, e dos quais o realismo aristotélico e o idealismo transcendental são os polos opostos. Daí a insistência com que Garcia Morente os coloca frente a frente, examinando-os, compreendendo-os no seu momento histórico, criticando-os, etc. O resto gira em tôrno dêsse vultos, ou como iniciação ou gestação (pré-socráticos, Sócrates, Platão; racionalismo, etc.) ou como consequência ou derivação (tomismo: idealismo post-kantista, etc.).

Como repensador compreensivo da problemática histórica da filosofia, Garcia Morente não se contenta com o expor, com o analisar; além de expor, situa; além de analisar, compreende; e porque situa e compreende, critica. Sim. García Morente não é simples historiador faticista; é um repensador dos fatos históricos da filosofia; e por isso, sua crítica, uma vêzes explícita, outras subentendida, segue o curso da análise e converte as excursões históricas, sem forçar a mente do pupilo, sem dogmatismo sistemático, em ensinamentos de verdadeira metafísica. São lições intercaladas, de ensino filosófico direto, a IX sôbre a fenomenologia do conhecimento, a XII sôbre a análise ontológica da fé, e as primeiras sôbre o método na filosofia. $\mathbf{E}$ chegamos com isso à segunda dimensão, porque ninguém ensina metafísica sem ser um metafísico; ninguém ensina filosofia sem ser verdadeiramente filósofo, sem ter um pensamento pessoal, original ou recebido, mas, sempre assimilado, personalizado, sôbre a problemática filosófica.

Porque Don Manuel foi um filósofo. Não um erudito da filosofia, mas um profissional com uma vocação realizada ao 
longo de tôda a sua vida. Não um funcionário da filosofia, como são a imensa maioria dos professôres correntes de filosofia, mas um filósofo integrado em corpo e alma na filosofia. Tôda a sua vida foi um viver filosófico, um viver de e para a filosofia, embora não exclusivamente de e para a filosofia. Yida humana profunda e nobre, porque ser filósofo é uma das mais difíceis e mais dignas formas de realizar-se como homem. E assim se realizou García Morente: pensando, vivendo, fazendo vida o pensamento, sendo seu próprio pensamento, tornando-se a realização dêsse pensamento. Creio que de nenhum de seus colegas de geração filosófica na Espanha pode-se dizer isto com tanta segurança e profundeza, como de García Morente. Outros levaram-lhe vantagem na originalidade do pensamento, na projeção e na importância histórica do mesmo; mas, em nenhum dêles, creio, o pensamento se absorveu tanto na estrutura do próprio viver, ou se se prefere, o pensamento brotou táo diretamente do viver, como em Garcia Morente. Por isso foi êle quem sofreu maior transformação no pensar porque foi quem sofreu maior transformação no viver. Imagino o caminhar vital de García Morente como um círculo de retôrno em que o ponto de partida e de chegada é a fé religiosa, atravessando uma longa etapa de arreligiosidade. $O$ importante para nós agora é que êste círculo de retôrno é a base para compreender a herança filosófica que nos legou e o significado de sua vida como filósofo. O lugar correspondente a García Morente no panorama da filosofia espanhola contemporânea é singular e diferente; enquanto outros seguiram uma linha mais ou menos reta rumo a um sistema, intuído no comêço embrionàriamente e que ia cada dia descobrindo-se, firmando-se, alargando-se, com maior ou menor fortuna, com maior ou menor originalidade, García Morente segue durante anos a fio na procura de fontes de verdade sem a preocupação de um sistema próprio inicialmente previsto ou intuído. Assim, vai deixando-se atrair pelas correntes filosóficas mais vivas do seu tempo: nas águas do seu kantismo inicial através da escola de Marburgo vão desembocando o pensamento de Bergson, a fenomenologia de Husserl, a etiologia de Max Scheler e confinantes, cada um com motivação diferente. $O$ bergsonismo oferece-lhe um tipo de método intuitivo e a oferta de uma realidade viva (oposta à conceitualizada ou estereotipada) 
que serão, para García Morente, aquisições definitivas; a fenomenologia o sensibiliza pelo seu processo para descobrir aspectos novos da realidade; e enfim, a filosofia dos valôres o atinge mais fundo, porque o tema dos valôres se consubstancia com sua problemática de catedrático de Ética e sua atitude vital radicada na ética. Porque García Morente, como pensamento e como vida, foi, ante tudo e em última instância, um ético; mas um ético inserto em metafísico. $\mathbf{E}$ por estar inserto em metafísico que o atraem com fôrça as filosofias contemporaneas que recolocam no centro do pensamento o problema do ser, construíndo-se sôbre êle; é por isto que se sente influído profundamente pelo existencialismo de Heidegger. A presença de Ortega y Gasset no pensamento de García Morente é caso à parte e por razões óbvias: de formação aproximada, cedo Ortega y Gasset encontrou o caminho do seu mundo filosófico que se foi perfilando, aprofundando sem cessar, até a estruturação de um organismo filosófico próprio. Poucos devem ter seguido tão de perto e tão passo a passo como García Morente o evoluir e as sucessivas conquistas da filosofia de Ortega; êste era para Morente a melhor experiência de contacto com uma grande mente filosófica, mente em convivência e amizade durante muitos anos. Já em 1935 escrevia Morente: "Eu conheci a don José Ortega y Gasset faz 27 anos... Foram 27 anos de convivência diária, de compenetração íntima. O senhor pode imaginar o que isto tem representado para mim?" A procura filosófica de Morente, despretenciosa de originalidade, encontrava a seu lado um rico manancial de meditação; e o aproveitou à vontade. Mas, parece exagêro afirmar, como o faz Julián Marias, que "a filosofia de Ortega constitui a base geral sôbre a qual se inseriu o trabalho pessoal de Morente ("La filosofia española actual", pg. 128 - Espæsa Calpe - Buenos Aires, Colección Austral, n. ${ }^{\circ}$ 804). Desde logo, tal asserção não tem qualquer cabimento referido à etapa final do pensamento de Morente, a que se inicia a partir da guerra civil espanhola. Porque a partir desta guerra, há uma reformulação total de sua visão da vida. A guerra civil espanhola foi um fato de extraordinária repercussão no seu viver e no seu pensar; a violência desabou sôbre sua família arrebatando-lhe alguns dos sêres mais queridos, assassinados na zona republicana. Êle próprio teve que sair da Espanha quase 
como foragido. $\mathrm{O}$ abalo sentimental (êle se julgava de uma "sensibilidade já de si subtil e excitável") revolveu todo seu interior; no fundo reaparece a fé religiosa, sua fé de criança perdida nos alvôres de seu racionalismo filosófico. Aquele filósofo descrente que anos atrás, nos funerais da espôsa, só conseguia interessar-se pela beleza da música sacra, agora em França, olhando para a pátria torturada pela guerra e para a família desfeita e longínqua, sente a necessidade de ajoelharse e murmurar orações da infância mal lembradas. García Morente nos deixou um relato emocionante dêste novo encontro com Deus; não o Deus de sua razão alto e frio ("concepção absurda e ímpia de Deus e de sua Providência", dirá êle em 1940), mas o Deus vivo e vivificante de sua fé católica. E um relato minucioso da transformação total do seu íntimo, verificada entre agôsto de 1936 e maio de 1937. A análise fenomenológica desta transformação - que segue passo a passo os estados sucessivos de seu espírito como repercussão de fatos externos na sua "super-estrutura ideológica" e que descobre, dialèticamente, a presença escondida do novo Deus providente que vai substituindo seu fatalismo racionalista - é uma maravilha de introspecção interior e de metodologia fenomenológica. O filósofo se toma a si próprio como objeto de análise na etapa mais decisiva de sua vida; e vemos em série dialética estritamente dialética, mas uma dialética de angústia, da própria vida, da própria existência: "o beco sem saída" de seu pensamento anterior em choque com os novos fatos; a antinomia "entre essa vida que não é minha, porque a fêz outro, e, no entanto, é minha porque só eu a vivo"; o "ruir da confiança na determinação natural de causas e efeitos"; a "pequena crise - a primeira - no meu dispositivo intelectual" etc., até que "a idéia providencialista" vai tomando conta da antinomia desfazendo-a, primeiro "por vias puramente abstratas e metafísicas" e depois com a revivescência na mente e no coração do Deus Homem ao qual Morente adere para sempre. E imaginar que na tensão dêste laboratório psico-metafísicoteológico, que foi a alma de Morente durante quase um ano, não faltou o fundo musical de uma sinfonia de Frank, da "Pavane pour une infante defunte" de Ravel e de "L'Infance de Jésus" de Berlioz! Que contraponto com o García Morente dos funerais de sua esposa! O resultado ideológico da evolução 
da crise foi a convicção da necessidade de "edificar o castelo filosófico sôbre novas bases" (ver a carta de Morente a Monsenhor Lahiguera, publicada pela editôra Aster, Lisboa-São Paulo, 1959, no volume de García Morente: Razão e Fé, pgs. $1-45$.

Assim: "novas bases para o castelo filosófico". Não ruptura com o passado, pois ao final, não estivera várias décadas filosofando em vão; não a eliminação sumária de seu viver filosófico anterior, mas a colocação em nova perspectiva - a perspectiva das novas bases - dos elementos, passiveis de integração, dêste viver. E Morente procura as novas bases. A partir dêste momento intensifica seu interêsse por determinada filosofia que se conformava melhor com os alicerces da nova fé católica, e que até então, talvez, só tivesse despertado sua atenção como fato histórico e não como sistema para ser substancialmente participado; e participa dela e acredito que com o tempo fez dela o núcleo do seu organismo filosófico. Refiro-me, é claro, ao tomismo tomado na sua expressão mais originária e pura, como um realismo moderado de portas abertas para tôdas as luzes da verdade. Nêsse organismo permaneceu atuante - talvez com nova polarização - tudo quanto no seu caminhar para a verdade tinha êle recolhido, carregado consigo; eram outros métodos próprios para outras perspectivas do ser e do viver, que não podiam ser desprezados, antes recolocados e integrados. Desde a tomada de consciência da necessidade de reformular seu passado fundindo-o no presente, começa Garcia Morente a reconstrução do seu último pensamento filosófico que não chegou a plenitude; a instância cada vez maior pela vivência religiosa pura que o levou mais tarde ao sacerdócio católico, afastou-o um pouco da pura filosofia; durante algum tempo viveu Morente, aos menos aparentemente, à margem da função filosófica, e sua vontade de dedicar-se simplesmente ao ministério de almas é o melhor sinal de que havia mudado o centro de gravidade do seu viver.

Sintetizando o referente à dimensão do pensamento pessoal de Morente, podemos dizer: seu último impulso foi um intento de integração das várias correntes filosóficas modernas sôbre a substância básica de uma filosofia tradicional, da filosofia perene. Nêste sentido o significado de Morente não se parece com nenhum outro filósofo hispano de sua geração. 
(O caso de Zubiri, que se encontra em parecida situação, é diferente pela diversidade de sua gênese filosófica).

E entramos na terceira dimensão, a da transmissão da filosofia. O ensino da filosofia é uma urgência do homem filósofo; o pensamento interior se complementa naturalmente com a comunicação, com a participação que o torna missão. Comunicação que é ensino; o ensino é, sobretudo, magistério, e magistério, na sua forma mais viva, é magistério oral. O magistério oral da filosofia foi exercido por todos os grandes filósofos que tiveram a oportunidade. Imaginamos o que foi para Morente a cátedra universitária de filosofia pelo que sabemos por seus melhores discípulos. Todos êles proclamam ter sido Morente o melhor professor de filosofia na Espanha durante as quatro primeiras décadas dêste século. Mas realmente não precisaríamos destas testemunhas, porque o presente livro é a melhor expressão do que era García Morente como professor de Filosofia. Livro essencialmente escolar, produto de umas aulas universitárias tomadas taquigràficamente, conserva êle as notas características do método pedagógico de Morente como professor de filosofia. Imediatamente o leitor deixa de sentir-se leitor para transformar-se em ouvinte, coparticipante do convívio de filosofia. Nêsse convívio tornamonos convivas e conviventes da filosofia, porque o mestre vai introduzindo-nos com uma luminosidade, com uma facilidade, com uma progressividade, que nos permite adaptar suavemente o intelecto ao choque com os mais duros problemas. Com êsse método - clareza, naturalidade, dialética - somos guiados ao tronco dos problemas quase que insensívelmente; sentimonos dentro dêles, capazes de tomar-lhes as medidas e equacioná-los. A facilidade não é uma forma de escamotear o caroço dos problemas; é um método para chegar a êles, para colocarnos frente a êles fazendo-nos apalpar suas asperezas, mas sem deixar-nos a sós com elas, antes rasgando luminosas frestas a possíveis soluções; é um caminho fácil para atingir as dificuldades da filosofia. Admirável a pedagogia de Morente para conquistar candidatos à meditação filosófica! Os temas mais abstrusos, os objetos filosóficos que mais apavoram ao neófito pela sua inexperiência no exercício filosófico, tornam-se acessíveis, quase que manuais. Mas, é claro, trata-se de uma iniciação, de um mergulho no mar da filosofia; de um convite 
convidativo para todo e qualquer intelecto que, insatisfeito com o fenomênico do mundo, experimenta a ânsia de penetrá-lo nas suas profundezas, na sua realidade ôntica. Depois, cada um deve decidir seu destino: ficar como aficionado ou aventurar-se a uma definitiva vocação de filósofo.

Leitor: êste livro é um longo colóquio para a filosofia; peço-lhe que interprete desde esta atitude coloquial alguns pormenores de expressão que, de outro modo, pareceriam literàriamente falhos. A lentidão com que o autor avança - devida a repetições, insistências, etc. - pode em certos momentos irritar o leitor que já conhece êstes problemas de filosofia. Gostaria que o leitor percebesse que tal lentidão é dialética, porque o guia não quer que seu acompanhante dê um passo em falso; por isso, as frases vão concatenando-se umas às outras como elos de um pensamento lógico, de um caminhar dialético que permite o avanço progressivo sempre sôbre terreno firme. filosófico, em que o principiante - solicitado pelas repetições - tem tempo (o tempo lento de todo comêço) para repensar cada etapa do desenvolvimento dos problemas. E como Morente facilita a tarefa! Essa tarefa de começar a ser filósofo, que é começar a pensar por si, começar a fazer seus os problemas da filosofia, de vivê-los desde nós mesmos! Se ser mestre da filosofia é ensinar a ser filósofo, iniciar na assimilação pessoal da problemática filosófica, poucos ganharão de Garcia Morente; porque poucos sabem, com igual maestria, despertar-nos para os problemas metafísicos e obrigar-nos a carregá-los conosco, a sentí-los, não como fantasmas no ar ou como uma bola que se apanha e se larga à vontade, mas como um pêso sôbre nossa vida, um pêso gravitando sôbre nosso viver de homens, de sêres pensantes (feitos de pensar e de pesar, de pesos e de pensamentos; saborosa e profunda raíz da etimologia!) cuja levitação só nós mesmos podemos realizar descobrindo em cada pêso uma asa para o vôo alto.

Uma palavra final sôbre a tradução. Respeitei rigorosamente o estilo coloquial da obra. Permiti-me sòmente pequenos retoques de correção, leves modificações em pouquíssimos pontos para suprir falhas que se devem às cópias taquigráficas não revistas pelo autor. Respeitei assim notas de estilo e o 
numeroso vocabulário que foge à língua comum; felizmente a semelhança de raízes semânticas e o paralelismo morfológico do espanhol e do português, facilitaram minha tarefa. $E$ por isso que vozes como "contingencialidades", "intuitividad", "causación", "cosación", "cosidad", "subsubregión", "incondicionalidad", "mencional", "valiosidad", "estante", etc., traduzi-as pelas correspondentes semânticas e morfológicas "contingencialidades, intuitividade, causação, coisação, sub-sub-região", etc. etc. 